\title{
Activity Disengagement: Understanding Challenges and Opportunities for Reengagement
}

\author{
Krista Fox, ${ }^{1}$ Nancy Morrow-Howell, ${ }^{2,3}$ Stephanie Herbers, ${ }^{3}$ \\ Paula Battista, ${ }^{2}$ and Carolyn M. Baum ${ }^{1,2,3}$ \\ ${ }^{1}$ School of Medicine, Program in Occupational Therapy, Washington University in St. Louis, St. Louis, MO, USA \\ ${ }^{2}$ George Warren Brown School of Social Work, Washington University in St. Louis, St. Louis, MO, USA \\ ${ }^{3}$ Institute for Public Health, Harvey A. Friedman Center for Aging, Washington University in St. Louis, St. Louis, MO, USA \\ Correspondence should be addressed to Carolyn M. Baum; baumc@wustl.edu
}

Received 23 September 2016; Accepted 13 December 2016; Published 12 January 2017

Academic Editor: Patricia Belchior

Copyright (C) 2017 Krista Fox et al. This is an open access article distributed under the Creative Commons Attribution License, which permits unrestricted use, distribution, and reproduction in any medium, provided the original work is properly cited.

\begin{abstract}
Although maintaining engagement in activities has a positive influence on our health and wellbeing as we age, many programs that serve older adults struggle with getting participation in the programs they offer. This study sought to explore activity disengagement among older adults in a senior housing community and identify the challenges and opportunities for reengagement with the aim of informing future intervention development and testing. Fifty-one adults over the age of 60 participated in structured interviews. Findings highlighted that many older adults have activities patterns that are not optimal for health. Many reasons given for disengaging in activities (e.g., no opportunity) were surprising given that participants lived in a setting where a variety of programs were offered. Programs need to more purposively address social challenges to participating in activities and consider a more person-centered approach when developing interventions for the older adults they serve.
\end{abstract}

\section{Background and Purpose}

The relationship between activity engagement and health is well documented. It has long been established that participation in activities, such as volunteer work, hobbies, visiting with friends, and exercise, produces both positive physical and mental health outcomes [1], reduces the risk of disabilities [2], and protects against cognitive decline and depressive symptoms $[3,4]$. More recent studies confirm these early findings, including a recent systematic review on occupational engagement and health-related outcomes in older adults, further supporting the notion that engagement in work, physical, community, leisure, and social activities promotes better health and quality of life among older adults [5]. Specifically, a randomized clinical trial using an activity intervention had a positive effect on pain, vitality, social functioning, mental health, and life satisfaction $[5,6]$.

Activity engagement is a pillar in two popular frameworks for healthy aging. The Successful Aging Paradigm [7] recognized the multidimensional constructs that in addition to avoiding disease and disability includes the maintenance of physical and cognitive function as critical to sustained engagement in social and productive activities. The World Health Organization's Active Aging Model [8] recognizes the process of optimizing opportunities for participation to enhance quality of life. As we face a growing population of older adults world-wide-increasing from $8 \%$ to $16 \%$ of the total population [8] - the factors associated with remaining active are essential to fostering healthy life years among older adults and promoting healthy communities.

Occupational therapy has long held theoretical assumptions about the importance of occupation in maintaining health [9-11]. Our leaders tell us that humans have an innate need to engage in occupation and that engagement will influence health. Law et al. and Creek and Hughes $[12,13]$, tell us that there is a relationship between what people do and their health. The profession seeks to understand human occupation, yet the definitions of occupation range from "chunks of activity" [14] to "actions, activities, and tasks" [15, 16]. Hasselkus [17] reminds us that occupation encompasses 
what people do as well as the meaning and context of their actions. The International Classification of Function, Disease, and Disability uses the term activity to describe the execution of a task or action [18]. We have chosen to use the term activity in this initial study of older adults as they understand it and we describe activity as what people do and want to do as we seek to understand barriers to that doing. Activity has always been central in programs serving the older population, including life-long learning programs, senior centers, daycare centers, and residential facilities of all types. The approach to activity engagement has primarily been "if we build it, they will come." That is, program staff members devise the activities offered-often with input from their consumers-and provide the opportunity to those who wish to avail themselves. This approach has enabled many older adults to engage in health-promoting activities. However, there are many older adults who do not engage in these programs. Their lack of engagement may be due to lack of availability, lack of knowledge, or lack of interest. Even when programs are readily available to older adults, these programs oftentimes are not utilized. To date, we do not know much about why older adults disengage in certain activities, why they do not attend organized activities, and what it may take for them to do activities that they enjoy again. It is essential to understand the factors influencing activity disengagement in order to improve programming that will engage older adults in health-promoting activities.

This paper reports pilot descriptive work to lay the foundation for an intervention to specifically identify the challenges and opportunities for reengagement of older adults as they experience individual and environmental limitations. The methods used for recruitment and interviews were not intended for generalization of study findings, rather the intent was exploratory to inform potential intervention development and testing.

\section{Methods}

2.1. Participants. Participants lived in a publically subsidized apartment complex for low income older adults aged 60 and older. The site offers enhanced health and social programming funded through grant and private money. Resources offered by the site included congregate meals, activity programs, and supportive social services. No in-home supportive services were provided. We chose the site as it offered a variety of activities for their residents and local older adults including art classes, field trips, a community garden, concerts, and wellness fairs. To participate in the study, individuals needed to be living independently in an apartment or home, 60 years or older, and able to complete an interview in English. Residents of the senior apartments and congregate meal participants that lived elsewhere in the community were considered eligible. A total of 51 participants, 42 females and 9 males, were recruited by facility staff using informational flyers posted throughout the building. Ages ranged from 63 to 93, averaging 78.7 years. Fifty-one percent of the sample was widowed, and $33.3 \%$ was divorced; there was only one participant who was married. Seventy-four percent of participants were retired; $14 \%$ were working part time. Anecdotally, this
TABLE 1: Participant characteristics $n=51$.

\begin{tabular}{|c|c|c|}
\hline Characteristic & $n$ & $\%$ \\
\hline \multicolumn{3}{|l|}{ Gender } \\
\hline Female & 42 & 82 \\
\hline Male & 9 & 18 \\
\hline \multicolumn{3}{|l|}{ Age } \\
\hline $60-69$ & 11 & 22 \\
\hline $70-79$ & 12 & 23 \\
\hline $80-89$ & 22 & 43 \\
\hline $90+$ & 6 & 12 \\
\hline \multicolumn{3}{|l|}{ Relationship status } \\
\hline Never married & 4 & 8 \\
\hline Married & 1 & 2 \\
\hline Separated & 3 & 6 \\
\hline Divorced & 17 & 33 \\
\hline Widowed & 26 & 51 \\
\hline \multicolumn{3}{|l|}{ Size of household } \\
\hline 1 person & 50 & 98 \\
\hline 2 people & 1 & 2 \\
\hline \multicolumn{3}{|l|}{ Highest grade in school completed } \\
\hline Less than high school graduate & 7 & 14 \\
\hline High school graduate & 11 & 22 \\
\hline Some college or technical school & 17 & 33 \\
\hline College graduate & 16 & 31 \\
\hline \multicolumn{3}{|l|}{ Employment status } \\
\hline Working, part- or full-time & 8 & 16 \\
\hline Unemployed, looking for work & 3 & 6 \\
\hline Retired & 38 & 74 \\
\hline Disabled, unable to work & 1 & 2 \\
\hline Never worked outside of home & 1 & 2 \\
\hline
\end{tabular}

sample reflected the majority of the residents in the apartment community; however, the study team did not collect demographic data for the entire facility. Additional demographic information on the sample is included in Table 1. Participants received ten-dollar gift cards for their time.

2.2. Data Collection. The Human Subjects Review Board at the study team's institution approved this study. Participants were privately interviewed in-person by a study team of four trained interviewers, consisting of occupational therapy and social work students whose work was focused on aging. Interviews started with obtaining consent and an overview of the study. The interview duration ranged from 45 to 75 minutes and included the administration of the Activity Card Sort and supplemental questions which probed the participants on the reasons for giving up or doing the activity less and what it would take for them to do these activities again. The interview portion was audio-recorded. Participants could skip any questions they preferred not to answer.

2.3. Measures. Data were collected via a structured interview. Activity engagement was measured using the Activity Card Sort (ACS) [19, 20], a set of 89 picture cards depicting older adults doing activities in four domains: instrumental (e.g., grocery shopping, and cooking), low-demand leisure (e.g., 


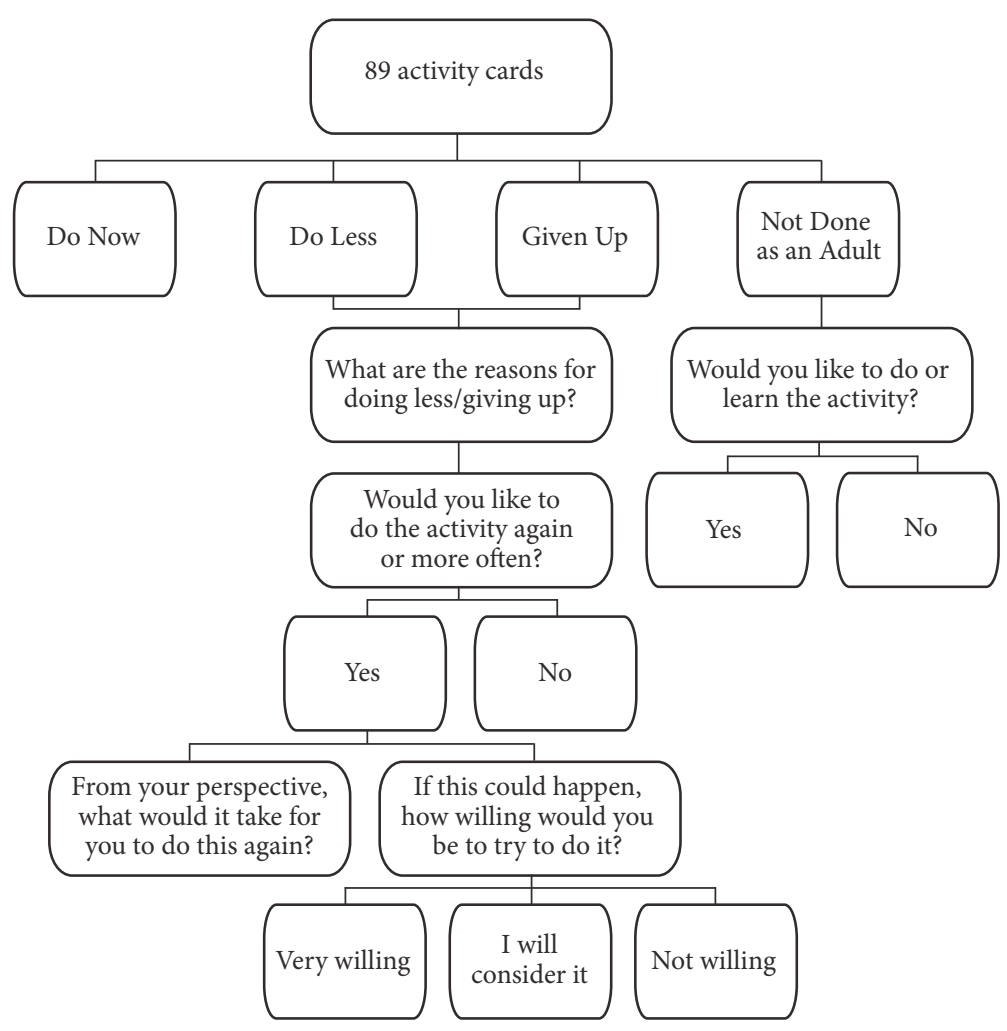

FIGURE 1: Flowchart of interview.

puzzles, watching movies), high-demand leisure (e.g., golfing, yoga/pilates), and social activities (e.g., parties, talking on the phone). The instrument uses a procedure that engages the interviewee in organizing the picture cards into groups designed to document the person's participation in activities. Reliability and validity have been well established in previous studies [21-25].

There are three versions of the ACS: institutional (for hospital, rehabilitation, and skilled-nursing settings), recovering (for individuals receiving outpatient or in-home services), and community-living (for individuals who do not necessarily have an illness or injury that requires specific treatment). The ACS was administered in this study using the procedures for the community-living version. Participants sorted the activity cards in context of the past year as "Do Now," "Do Less," "Given Up," or "Not Done as an Adult."

The card sort was followed by supplemental questions identifying barriers and facilitators to the participation in and performance of activities. For each activity in the "Do Less" or "Given Up" category, residents were asked the reasons for decreased activity level. They could choose from a list of barriers (e.g., "Physically Difficult," "No Opportunity," "No One to Do It with") or identify other reasons. If they reported that the activity was one they would like to do again or more often, the interviewer asked what it would take for them to do it again. This was an open-ended question without visual prompts, but if the participant struggled with an answer, the interviewer would refer to the barriers they mentioned to help facilitate thought. Finally, the interviewer asked for their level of willingness to reengage in activities they would like to do again or more often (i.e., not willing, will consider it, and very willing). For the activities categorized as "Not Done as an Adult, " the participants were asked if they would like to do or learn the activity. Figure 1 illustrates this interview process, from the card sort through the supplemental questions. The interview concluded with demographic questions addressing age, household size, employment status, marital status, and educational attainment.

2.4. Data Analysis. Data analysis was completed using SPSS statistical software [26]. Frequency statistics identified common activities in each of the sorted categories, common barriers and facilitators, and willingness levels to reengage. Barriers and facilitators to activities were calculated based on ACS domains by percentage of respondents who reported that barrier or facilitator for at least one activity in the domain. The facilitators were based on responses to an openended question. Categories were formed based on common responses such as "If I had someone to do it with" or "Transportation." Two coders reviewed responses and developed categories, group consensus resolved discrepancies. Categorizing the facilitators allowed for quantification in the data analysis.

\section{Results}

3.1. Current Activities of Participants. The most common current activities of participants were instrumental (e.g., going to the doctor, paying bills) and low-demand leisure 
TABLE 2: Top ten activities participants have given up or are doing less.

\begin{tabular}{lc}
\hline Activity & Given up or do less $n(\%)$ \\
\hline Yard maintenance & $36 / 36(100 \%)$ \\
Child care & $36 / 38(94.7 \%)$ \\
Work (paid) & $35 / 44(79.5 \%)$ \\
Being with a spouse or partner & $35 / 37(94.6 \%)$ \\
Dancing & $35 / 41(85.4 \%)$ \\
Entertaining at home or club & $33 / 40(82.5 \%)$ \\
Household maintenance & $30 / 37(81.0 \%)$ \\
Parties/picnics & $30 / 48(62.5 \%)$ \\
Taking care of a pet & $30 / 38(78.9 \%)$ \\
Dating/spending time with friends & $28 / 44(63.6 \%)$ \\
\hline
\end{tabular}

Note. Denominator represents those who have done the activity as an adult.

(e.g., sitting and thinking, watching television). The following lists the top ten activities participants maintained by the 51 older adults:

(1) Going to the doctor or therapy (50)

(2) Shopping for groceries (48)

(3) Watching television (47)

(4) Paying bills (46)

(5) Laundry (44)

(6) Sitting and thinking (42)

(7) Taking out the trash (42)

(8) Listening to music (41)

(9) Reading magazines/books (41)

(10) Resting (40)

(n) represents the number of participants out of 51 who responded with "do now."

The most common activities participants had given up or were doing less were instrumental activities (e.g., yard maintenance) and social activities (e.g., being with a spouse or partner). Table 2 shows the top ten most common activities reported as "Do Less" or "Given Up." Table 2 ranks activities by the total number of people. For example, the highest number of participants $(n=36)$ had reported disengagement in yard work and childcare.

Additionally, there was a set of activities with very high levels of disengagement, although few people ever did them. For example, only 21 residents had ever gone fishing as an adult, and of those, 20 (95.3\%) had not maintained their previous activity level. Other activities with high disengagement percentages included camping $(100 \%, n=21)$, canoeing/boating/sailing (100\%, $n=16)$, and bowling $(95.6 \%, n=24)$.

3.2. Barriers to Activities. Table 3 shows the most common reasons participants identified for giving up or doing activities less. "No Opportunity" was the reason identified by $78 \%$ of participants for instrumental activities; the reason was often due to living in an apartment building (e.g., no need for yard
TABLE 3: Most common barriers by activity domain $(n=51)$.

\begin{tabular}{lcc}
\hline Activity domain & Barrier & $\%(n)$ \\
\hline \multirow{2}{*}{ Instrumental } & No Opportunity & $78.4 \%(40)$ \\
& No Interest & $51.0 \%(26)$ \\
\hline \multirow{3}{*}{ Low demand leisure } & No Interest & $86.3 \%(44)$ \\
& No Opportunity & $74.5 \%(38)$ \\
& No One to Do It with & $62.7 \%(32)$ \\
\hline \multirow{2}{*}{ High demand leisure } & Physically Difficult & $76.5 \%(39)$ \\
& No Opportunity & $66.7 \%(34)$ \\
\hline \multirow{3}{*}{ Social } & No One to Do It with & $84.3 \%(43)$ \\
& No Opportunity & $76.5 \%(39)$ \\
& Physically Difficult & $66.7 \%(34)$ \\
\hline \multirow{2}{*}{ All activities } & No Opportunity & $94.1 \%(48)$ \\
& No Interest & $90.2 \%(46)$ \\
& Physically Difficult & $86.3 \%(44)$ \\
& No One to Do It with & $76.5 \%(39)$ \\
\hline
\end{tabular}

maintenance). "No Interest" was the most common reason for low-demand leisure activities such as photography or interior decorating. As would be expected, being "Physically Difficult" was the most common reason for giving up high-demand leisure activities (e.g., playing team sports, hiking) and "No One to Do It with" was the most common reason for social activities (e.g., dancing, being with a partner, and traveling).

When strictly considering activities that the residents reported they would like to do again or more often, the most common barrier for instrumental, low-demand leisure, and high-demand leisure was "No Opportunity"; for social activities it remained "No One to Do It with." Other barriers which did not have high frequencies in any domain were getting tired, being afraid of falling, getting frustrated, no transportation, not enough money, not having supplies, not having space, needing assistance, having assistance and no longer needing to do activity, and not having time.

3.3. Facilitators for Activities. Table 4 shows the most common answers to the question "What would it take to do it again?" for activities that participants reported they wanted to do again or more often. "Someone to Do It with Me" was the most common answer among the five activity categories, especially for social activities. To do instrumental activities again, participants identified needing more opportunities, more money, or having the supplies. A combination of "Someone to Do It with Me" and "Opportunity" was reported for high-demand leisure activities. Other facilitators which were not high in frequency included more energy, better physical health, transportation, more money, assistance, more time, and more space.

3.4. Activities Participants Would Like to Do. Table 5 shows the top ten activities participants reported they would like to do again or more often. These top ten activities are mostly low-demand leisure activities (e.g., attending concerts, going to the theater) and some social activities (parties/picnics, visiting friends). It is important to note that there may be 
TABLE 4: Most common facilitators by activity domain $(n=51)$.

\begin{tabular}{lcc}
\hline Activity domain & Facilitator & $\%(n)$ \\
\hline \multirow{2}{*}{ Instrumental } & Opportunity & $39.2 \%(20)$ \\
& More Money & $39.2 \%(20)$ \\
\hline \multirow{2}{*}{ Low demand leisure } & Someone to Do It with Me & $54.9 \%(28)$ \\
& Opportunity & $41.2 \%(21)$ \\
\hline \multirow{2}{*}{ High demand leisure } & Someone to Do It with Me & $72.6 \%(37)$ \\
& Opportunity & $72.6 \%(37)$ \\
\multirow{2}{*}{ Social } & Someone to Do It with Me & $70.6 \%(36)$ \\
& Opportunity & $47.1 \%(24)$ \\
\hline \multirow{2}{*}{ All activities } & Someone to Do It with Me & $80.4 \%(41)$ \\
& Opportunity & $78.4 \%(40)$ \\
\hline
\end{tabular}

TABLE 5: Top ten activities participants would like to do again or more often.

\begin{tabular}{lcc}
\hline Activity & $\begin{array}{c}\text { Would like to } \\
\text { do again or } \\
\text { more often }\end{array}$ & \# very willing \\
\hline $\begin{array}{l}\text { (1) Going to the } \\
\text { theater } \\
\text { (2) Going to }\end{array}$ & $16 / 26(76.9 \%)$ & 15 \\
garden or park \\
$\begin{array}{l}\text { (3) Traveling } \\
\text { local/regional }\end{array}$ & $18 / 25(72.0 \%)$ & 13 \\
$\begin{array}{l}\text { (4) Attending } \\
\text { concerts }\end{array}$ & $20 / 30(66.7 \%)$ & 12 \\
$\begin{array}{l}\text { (5) Parties/picnics } \\
\text { (6) Going to the }\end{array}$ & $15 / 19(78.9 \%)$ & 12 \\
$\begin{array}{l}\text { museum } \\
\text { (7) Visiting with } \\
\text { friends } \\
\text { (8) Walking }\end{array}$ & $17 / 25(68.0 \%)$ & 12 \\
$\begin{array}{l}\text { (9) Visiting with } \\
\text { family/friends } \\
\text { who are ill } \\
\text { (10) Watching }\end{array}$ & $14 / 20(70.0 \%)$ & 11 \\
movies & $18 / 27(66.7 \%)$ & 11 \\
\hline
\end{tabular}

Note. Denominator represents those who have given up the activity or done it less.

a gap between what individuals say they might want to do and what they actually do. Although this gap cannot be known through this survey, this gap is suggested in Table 5 with ratings of willingness to engage in the activity. For some activities, there seem to be high levels of willingness to participate. For example, $80 \%$ of the respondents reporting that they wanted to go to the theater also reported that they would be very willing to engage in that activity if offered (16/20 respondents). Eighty percent (12/15) of those who said they would like to attend concerts also said they would be very willing to go if the opportunity was offered. However, at the other extreme, only $57 \%$ of the respondents who said they would like to engage in parties and picnics indicated that they would be very willing to participate if they were offered the opportunity.
The common new activities that participants wanted to do or learn, from those they had not done as an adult, were mostly low-demand and high-demand leisure. These included yoga/pilates/tai chi $(n=8)$, golfing $(n=7)$, bird watching $(n=5)$, playing a musical instrument $(n=5)$, cooking as a hobby $(n=4)$, sewing $(n=4)$, computer $(n=4)$, drawing/painting $(n=4)$, and hiking $(n=4)$.

\section{Discussion}

The aims of this project were to understand activity disengagement among older adults and identify challenges and opportunities for reengagement in the face of both individual and environmental limitations. The ultimate goal of this pilot study is to develop and test an intervention for reengagement in valued activities. Findings are useful in regard to both increasing the knowledge base on activity engagement and suggesting intervention approaches to increase engagement.

The current activities of residents, those that have been maintained in adulthood, were largely instrumental and of low-demand leisure. Interestingly, the most widely endorsed current activity was going to the doctor. Although frequency of medical appointments probably varies a great deal in the study sample, this finding highlights the need for transportation to support this important activity. Four of the top ten current activities involved tasks of daily living-shopping, paying bills, taking out trash, and laundry-and tasks that may be important to the individual's sense of competency and independence. Half of the most common activities were very low-demand leisure-watch TV, sitting and thinking, listening to music, reading, and resting. Although these activities may be important to self-care, enjoyment, and cognitive stimulation, these activities do not involve much physical exertion or social interaction. In sum, the current activity portfolios of the study participants most likely carry some value; but they fall short in other health-promoting aspects of activity engagement.

Findings indicated that activities that were given up or done less were more likely to be instrumental and social. These patterns of disengagement are partially explained by contextual factors. Childcare and paid work could be dropped as social roles change across the life course. Another life stage context of widowhood may explain changes in being with spouse or partner. In addition, the context of living in congregate housing clearly affected activity engagement of residents. After moving to their current apartments, residents no longer had the responsibilities of some instrumental tasks (e.g., yard and household maintenance are performed by facility staff). For some residents, this assistance with chores of daily living is a necessary and welcomed relief. For others, it may deprive them of valued activities, important to their identities and daily routines. No longer taking care of a pet may also be related to living in a high-rise congregate housing facility, and, in some cases, this activity loss could be harmful to the individual's wellbeing. In sum, life course transitions are associated with changes in activities, as well as social and housing contexts in which older adults live.

The findings regarding most frequently reported barriers suggest some interesting insights. The top two barriers 
listed were "No Opportunity" and "No One to Do It with." Housing staff members were indeed surprised to learn that residents reported these specific barriers, since the housing facility offers a variety of activities and residents live in close proximity to many other older adults. Oftentimes, a respondent would say they did not have the opportunity to do something even though such an activity was offered (e.g., gardening, singing in a choir). This finding suggests that even when opportunity exists, individuals are often uninformed or unable to recognize the opportunity as something for them. This finding also clearly challenges the idea that just building it or offering it is sufficient.

The perception of not having anyone to do an activity with is also perplexing since these study participants live in buildings with many other people, many of whom are similar in age, ethnicity, socioeconomic status, and so forth. This finding suggests that residents in housing complexes may know the people in their building and have friendly exchanges but not feel comfortable with them as activity companions or friends. Kemp et al. [27] examined the relationship patterns for residents in assisted living and developed a framework to describe factors contributing to residents' social careers. Among these factors, attitudes, personal characteristics (age, race, and culture), and level of health and functional status were very influential on relationship development. Attitudes about living in assisted living and social preferences often dictated behaviors in social interactions among coresidents. Similar personal characteristics encouraged relationships, and residents with lower functional status often were helped by their nearby coresidents, contributing to a closer relationship. Socioemotional selectivity theory [28] offers some additional explanation. This theory suggests that older adults often hone down friendship networks to devote energy to the most valued subset of relationships. The investment of time and energy into new friendships may not be a high priority. The challenge is thus to find ways for individuals to accept the companionship of another person to facilitate activity engagement, perhaps without the demand for friendship until friendships can form in a more natural way.

This study suggests several points for consideration in intervention development. First, findings about current activities of this study sample demonstrate that many older individuals have activity patterns that are not optimal to health, given their low physical demand and their lack of social connection. We also think it will be necessary to explore the actual process of self-selecting and planning activities that are important to the individual. Thus, findings support the importance of developing a specific intervention to help older adults identify their options for engagement in meaningful activities. It is our hope that, through engagement in these self-identified meaningful activities, older adults' need for physical and social engagement will be addressed in order to maximize health outcomes. Second, although older individuals may live in an environment that seems ideal for activity engagement, given activity programming in the housing complex and the number of residents in close proximity, many individuals do not sense the opportunity or the availability of people to do things with. This suggests that these challenges must be confronted more purposively in interventions.

Intervention development might utilize the idea from socioemotional selectivity theory that individuals are more likely to invest their available resources in activities that have meaning to them. The card sort used to identify current and dropped activity patterns was also used to identify activities in which the individual would like to reengage, increase engagement, or try for the first time. It seems that these identified activities hold value for the person and offer a good starting point for increasing activity. In other words, the intervention does not start with the offering of any activity - it starts with identification of a valued activity for the individual. It is noteworthy that the activities identified for engagement seem quite attainable-going to places (e.g., theaters, parks, and museums), visiting people, and walking.

As findings of this study illuminated, the gap between reporting the desire to engage in an activity and actual engagement may be large. Clearly, personal barriers and facilitators must be addressed to reduce the gap between identifying the activity and actually taking steps toward engagement. Any intervention may require an individual problem-solving approach to increase the likelihood of engagement. Strategies from the Person-Environment-Occupation Model may be instructive to intervention development: change the person, change the activity, or change the environment [29]. In the model, changing the person is accomplished through rehabilitative services or exercises for recovery or remediation. Changing the activity involves strategic scheduling, fatigue management, planning ahead, and organizing. Changing the environment can include home modifications or rearrangement, using assistive technology or devices, utilizing social support, and accessing information or other resources.

There are limits to this pilot study that must be acknowledged. The sample was small and self-selected; thus, there are major limits to generalizability. The sorting category "Not Done as an Adult" was not specifically defined, which may have allowed residents to interpret the time frame differently. The information about activity engagement is self-reported, leading to the influence of social desirability on responses.

Despite these limitations, this pilot study has important implications. First, it appears that activity disengagement in later life can be understood in ways that can lead to interventions to increase activity and thereby promote health of older adults. That is, research can illuminate what activities are given up and why and what it might take for an individual to reengage, increase engagement, or initiate new engagements. This knowledge is the first step toward more successful models of activity interventions. Secondly, study participants' perceptions that there are no opportunities or no one to do activities with highlights limitations to the traditional approach of offering classes, group activities, or outings. This disconnect might call for another approach, a more personcentered approach that starts with the individual identifying valued activities and addresses their unique barriers and facilitators for reengagement. Finally, future research can employ a larger and more representative sample to increase knowledge of activity disengagement among diverse older adult populations and in different community environments. 


\section{Ethical Approval}

This study was approved by the Washington University in St. Louis Institutional Review Board (IRB\#201212125).

\section{Competing Interests}

The authors declare that there is no conflict of interests regarding the publication of this paper.

\section{Acknowledgments}

This study has been presented at the Gerontological Society of America's Annual Scientific Meeting in November 2014, Washington, DC. This research received no specific grant from any funding agency in the public, commercial, or notfor-profit sectors.

\section{References}

[1] W. B. Stav, T. Hallenen, J. Lane, and M. Arbesman, "Systematic review of occupational engagement and health outcomes among community-dwelling older adults," American Journal of Occupational Therapy, vol. 66, no. 3, pp. 301-310, 2012.

[2] C. F. Mendes de Leon, T. A. Glass, L. A. Beckett, T. E. Seeman, D. A. Evans, and L. F. Berkman, "Social networks and disability transitions across eight intervals of yearly data in the New Haven EPESE," The Journals of Gerontology-Series B Psychological Sciences and Social Sciences, vol. 54, no. 3, pp. S162-S172, 1999.

[3] S. S. Bassuk, T. A. Glass, and L. F. Berkman, "Social disengagement and incident cognitive decline in community- dwelling elderly persons," Annals of Internal Medicine, vol. 131, no. 3, pp. 165-173, 1999.

[4] D. F. Hultsch, C. Hertzog, B. J. Small, and R. A. Dixon, "Use it or lose it: engaged lifestyle as a buffer of cognitive decline in aging?" Psychology and Aging, vol. 14, no. 2, pp. 245-263, 1999.

[5] J. Jackson, M. Carlson, D. Mandel, R. Zemke, and F. Clark, "Occupation in lifestyle redesign: the well elderly study occupational therapy program," American Journal of Occupational Therapy, vol. 52, no. 5, pp. 326-336, 1998.

[6] F. Clark, J. Jackson, M. Carlson et al., "Effectiveness of a lifestyle intervention in promoting the well-being of independently living older people: results of the Well Elderly 2 Randomised Controlled Trial," Journal of Epidemiology and Community Health, vol. 66, no. 9, pp. 782-790, 2012.

[7] J. W. Rowe and R. L. Kahn, "Successful aging," Aging Clinical and Experimental Research, vol. 10, no. 2, p. 142, 1998.

[8] National Institute on Aging, National Institutes of Health, US Department of Health and Human Services, and World Health Organization, Global Health and Aging, NIH Publication No. 117737, 2011.

[9] A. Meyer, "The philosophy of occupation therapy," American Journal of Physical Medicine \& Rehabilitation, vol. 1, no. 1, pp. 1-10, 1922.

[10] M. Reilly, "Occupational therapy can be one of the great ideas of 20th century medicine," The American Journal of Occupational Therapy, vol. 16, pp. 1-9, 1962.

[11] A. Wilcock, "A theory of the human need for occupation," Journal of Occupational Science, vol. 1, no. 1, pp. 17-24, 1993.
[12] M. Law, S. Steinwender, and L. Leclair, "Occupation, health and well-being," Canadian Journal of Occupational Therapy, vol. 65, no. 2, pp. 81-91, 1998.

[13] J. Creek and A. Hughes, "Occupation and health: a review of selected literature," British Journal of Occupational Therapy, vol. 71, no. 11, pp. 456-458, 2008.

[14] E. J. Yerxa and S. B. Locker, "Quality of time use by adults with spinal cord injuries," The American Journal of Occupational Therapy, vol. 44, no. 4, pp. 318-326, 1990.

[15] C. Christiansen and C. Baum, Eds., Occupational Therapy: Overcoming Human Performance Deficits, Slack, Thorofare, NJ, USA, 1991.

[16] J. Craik, E. Townsend, and H. Polatajko, "Introducing the new guidelines-Enabling Occupation II: Advancing an Occupational Therapy Vision for Health, Well-being, \& Justice through Occupation," Occupational Therapy Now, vol. 10, no. 1, pp. 3-5, 2008.

[17] B. R. Hasselkus, "Eleanor clarke slagle lecture the world of everyday occupation: real people, real lives," American Journal of Occupational Therapy, vol. 60, no. 6, pp. 627-640, 2006.

[18] World Health Organization, "International Classification of Functioning, Disability and Health," 2011, http://www.who.int/ classifications/icf/en/.

[19] C. M. Baum and D. Edward, Activity Card Sort, AOTA Press, Bethesda, Md, USA, 2nd edition, 2008.

[20] D. F. Edwards and C. M. Baum, "The Activity Card Sort: a measure of participation in older adults," The Gerontologist, vol. 44, 152, 23, 2004.

[21] N. Katz, H. Karpin, A. Lak, T. Furman, and A. HartmanMaeir, "Participation in occupational performance: reliability and validity of the activity card sort," OTJR Occupation, Participation and Health, vol. 23, no. 1, pp. 10-17, 2003.

[22] V. W. K. Chan, J. C. C. Chung, and T. L. Packer, "Validity and reliability of the activity card sort-Hong Kong version," OTJR Occupation, Participation and Health, vol. 26, no. 4, pp. 152-158, 2006.

[23] E. Orellano, W. I. Colón, and M. Arbesman, "Effect of occupation- and activity-based interventions on instrumental activities of daily living performance among communitydwelling older adults: a systematic review," American Journal of Occupational Therapy, vol. 66, no. 3, pp. 292-300, 2012.

[24] R. Hamed and M. B. Holm, "Psychometric properties of the Arab Heritage Activity Card Sort," Occupational Therapy International, vol. 20, no. 1, pp. 23-34, 2013.

[25] A. Laver-Fawcett, L. Brain, C. Brodie, L. Cardy, and L. Manaton, "The face validity and clinical utility of the activity card sortUnited Kingdom (ACS-UK)," British Journal of Occupational Therapy, vol. 79, no. 8, pp. 492-504, 2016.

[26] IBM Corp, IBM SPSS Statistics for Windows, Version 22.0, IBM Corp, Armonk, NY, USA, 2013.

[27] C. L. Kemp, M. M. Ball, C. Hollingsworth, and M. M. Perkins, "Strangers and friends: Residents' social careers in assisted living," Journals of Gerontology-Series B Psychological Sciences and Social Sciences, vol. 67, no. 4, pp. 491-502, 2012.

[28] L. L. Carstensen, "The influence of a sense of time on human development," Science, vol. 312, no. 5782, pp. 1913-1915, 2006.

[29] C. H. Christiansen, C. M. Baum, and J. Bass-Haugen, "Personenvironment-occupation-performance: an occupation-based framework for practice," in Occupational Therapy: Performance, Participation, and Well-Being, Slack, Thorofare, NJ, USA, 2005. 


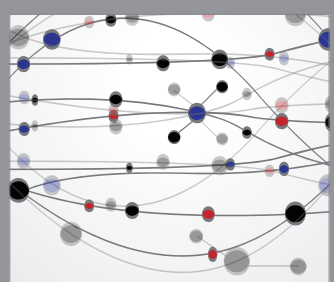

The Scientific World Journal
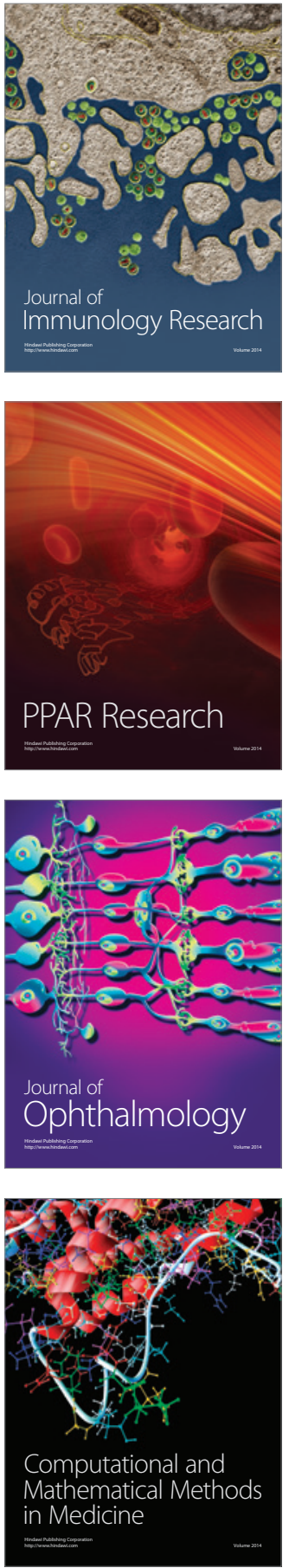

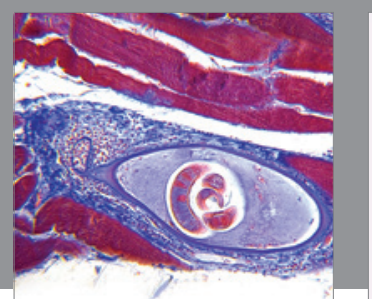

Gastroenterology Research and Practice
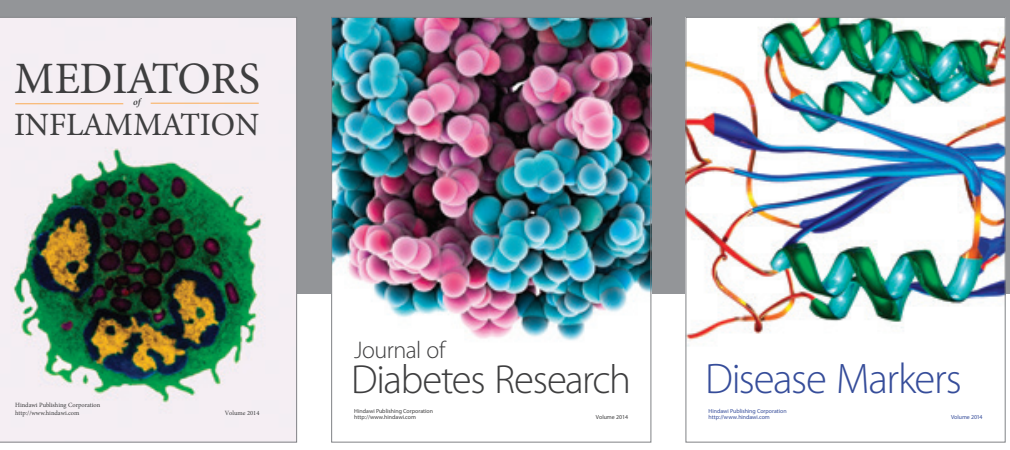

Disease Markers

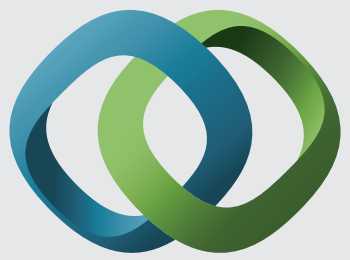

\section{Hindawi}

Submit your manuscripts at

https://www.hindawi.com
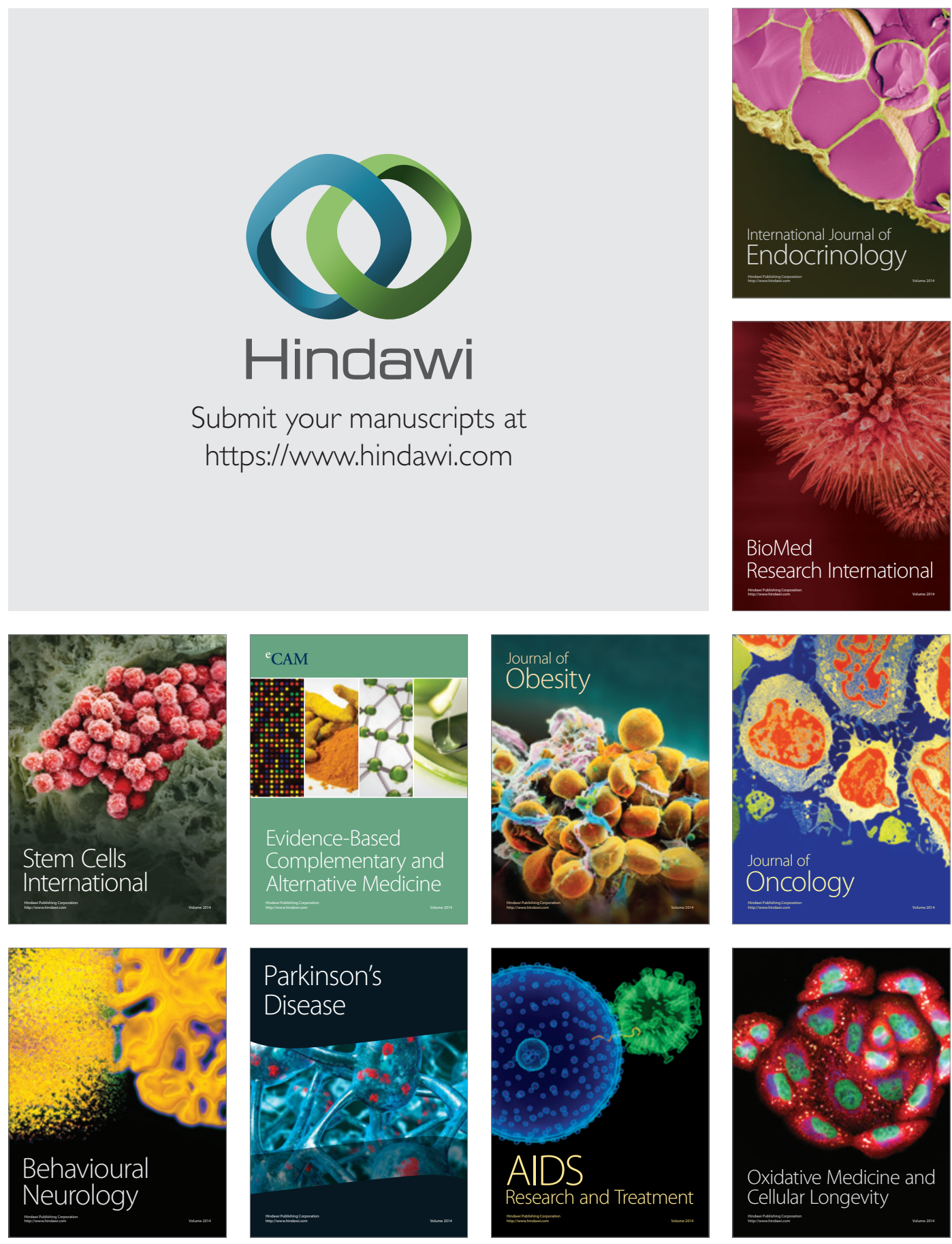